University of Nebraska - Lincoln

DigitalCommons@University of Nebraska - Lincoln

1997

\title{
Sites Other Than Nucleotide 234 Determine Cardiovirulence in Natural Isolates of Coxsackievirus B3
}

Nora M. Chapman

University of Nebraska Medical Center, Omaha, Nebraska

Jose R. Romero

University of Nebraska Medical Center, Omaha, Nebraska

Mark A. Pallansch

Centers for Disease Control and Prevention, Atlanta, Georgia

Steven Tracy

University of Nebraska Medical Center, Omaha, Nebraska

Follow this and additional works at: https://digitalcommons.unl.edu/publichealthresources

Part of the Public Health Commons

Chapman, Nora M.; Romero, Jose R.; Pallansch, Mark A.; and Tracy, Steven, "Sites Other Than Nucleotide 234 Determine Cardiovirulence in Natural Isolates of Coxsackievirus B3" (1997). Public Health Resources. 7.

https://digitalcommons.unl.edu/publichealthresources/7

This Article is brought to you for free and open access by the Public Health Resources at DigitalCommons@University of Nebraska - Lincoln. It has been accepted for inclusion in Public Health Resources by an authorized administrator of DigitalCommons@University of Nebraska - Lincoln. 


\title{
Sites Other Than Nucleotide 234 Determine Cardiovirulence in Natural Isolates of Coxsackievirus B3
}

\author{
Nora M. Chapman, ${ }^{1 *}$ José R. Romero, ${ }^{2}$ Mark A. Pallansch, ${ }^{3}$ and Steven Tracy ${ }^{1}$ \\ ${ }^{1}$ Department of Pathology and Microbiology, University of Nebraska Medical Center, Omaha, Nebraska \\ ${ }^{2}$ Department of Pediatrics, University of Nebraska Medical Center, Omaha, Nebraska \\ ${ }^{3}$ Enterovirus Diagnostic Laboratory, Division of Viral and Rickettsial Diseases, Centers for Disease Control and \\ Prevention, Atlanta, Georgia
}

The genetic site(s) that naturally determine the cardiovirulence phenotype of coxsackievirus B3 (CVB3) have yet to be mapped. Using two closely related CVB3 strains that differed in terms of cardiovirulence phenotype in mice, we previously reported the difference in phenotype mapped to a single site, nucleotide 234 (nt234) in the $5^{\prime}$ non-translated region (NTR) of the CVB3 genome. When nt234 was $C$, the virus was attenuated and when $U$, the virus was cardiovirulent. To determine whether this finding was applicable to other strains of CVB3, we examined 13 different naturally occurring CVB3 strains isolated in different years in the United States. We determined that only two isolates induced severe inflammatory heart muscle disease in $\mathrm{C} 3 \mathrm{H} /$ HeJ male mice. Using PCR products as sequencing templates, we determined the $5^{\prime}$ NTR sequence from each viral genome. Alignment of these sequences and other published CVB3 5' NTR sequences suggests as many as four separate lineages, with commonly used laboratory strains clustering closely in one branch. An examination of the sequences showed that regardless of cardiovirulence phenotype, nt234 was invariably uridine. Thus, the previously reported cytidine at nt234 is most likely the result of a rare mutation and is not a naturally occurring variation and other sites must account for the variance in virulence seen in natural isolates of CVB3. J. Med. Virol. 52:258-261, 1997.

KEY WORDS: coxsackievirus B3; virulence; $5^{\prime}$ non-translated region

\section{INTRODUCTION}

Coxsackievirus B3 (CVB3) is a typical human enterovirus (Picornaviridae) with a 7,400 nucleotide genome including a 741 nucleotide $5^{\prime}$ non-translated region
(NTR) [Tracy et al., 1996; Klump, 1990; Tracy et al., 1992; Chapman et al., 1994]. Coxsackievirus B3 is a cause of inflammatory heart muscle disease in both children and adults on the basis of isolation of infectious virus and serological studies [reviewed in Martino et al., 1995]. In addition, CVB3-induced murine acute inflammatory heart muscle disease (myocarditis) resembles many aspects of the homologous disease in man [Woodruff, 1980; Tracy et al., 1996].

Using two genetically similar strains of CVB3 that differed by murine cardiovirulence phenotype, we previously identified nucleotide 234 (nt234) in the $5^{\prime}$ NTR of the CVB3 genome as the primary determinant of the phenotype for these two viral strains [Tu et al., 1995]. The avirulent strain, CVB3/0 [Gauntt et al., 1979], is genotypically differentiable from the cardiovirulent strain, CVB3/20 [Tracy et al., 1992], in having a C rather than a $U$ at nt234 [Chapman, 1994], a change that results in an attenuated phenotype. To determine the applicability of these findings to other CVB3 strains, we examined naturally occurring strains of CVB3 for cardiovirulence phenotype in mice and the identity of nt234.

\section{MATERIALS AND METHODS Virus Strains}

Thirteen natural isolates of CVB3 were used for this study. Virus isolates were derived from different years in the United States. Strains AS, CO, DO, GA, GU, OL, $\mathrm{RE}, \mathrm{ZU}$ were the kind gift from D. Schnurr, California Department of Health Sciences, Berkeley, CA [Gauntt and Pallansch, 1996]. Strains 1699, 5965, D7783, 3175, 8680 were obtained from the Centers for Disease Control and Prevention [Gauntt and Pallansch, 1996]. All

\footnotetext{
*Correspondence to: Nora M. Chapman, Department of Pathology and Microbiology, University of Nebraska Medical Center, Omaha, NE 68198.
}

Accepted 29 January 1997 

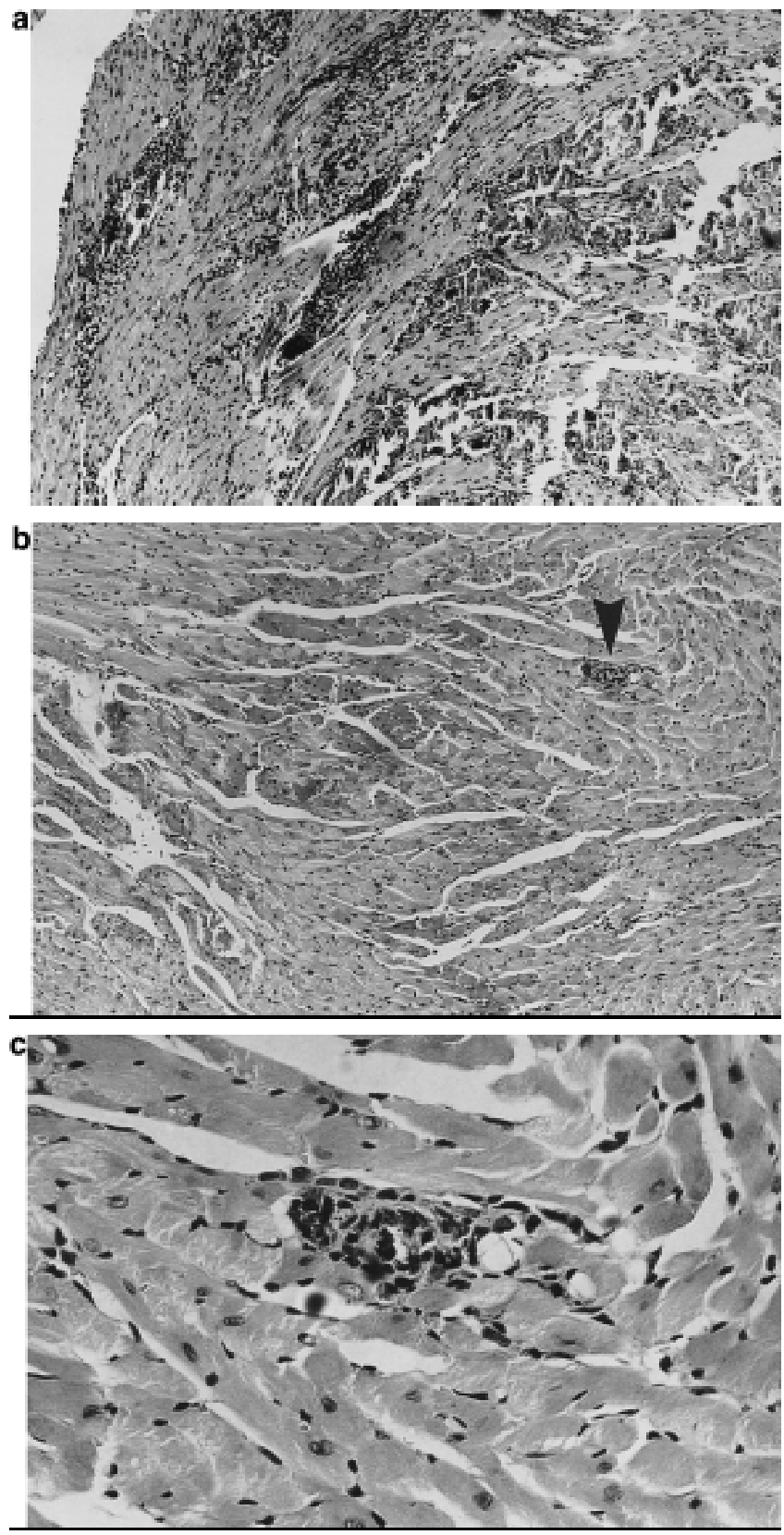

Fig. 1. Typical examples of thin sections of murine hearts from $\mathrm{C} 3 \mathrm{H} / \mathrm{HeJ}$ male mice infected with (a) cardiovirulent strain CVB3/AS or (b) avirulent strain CVB3/ZU at day 10. Arrowhead denotes small lesion in (b), which is seen at higher magnification (c). Hematoxylin and eosin stained, $100 \times(\mathrm{a}, \mathrm{b})$ or $400 \times(\mathrm{c})$.

stocks were prepared from low MOI infections, titered and stored frozen in aliquots until use.

\section{Inoculation of Mice}

$\mathrm{C} 3 \mathrm{H} / \mathrm{HeJ}$ male mice (Jackson Laboratories) at 3-4 weeks of age were rested until body weights were between $12-15 \mathrm{~g}$ per mouse. Groups of five mice were inoculated intraperitoneally with $2 \times 105$ TCID $_{50}$ virus in $0.1 \mathrm{ml}$ unsupplemented medium, then sacrificed 10 days later. Mouse hearts were formalin fixed, then embedded in paraffin. Six 5-6- $\mu$ thick sections were cut, with each section separated by five to six similarly cut sections. Hematoxylin and eosin stained heart sections were examined by light microscopy for the presence of inflammatory lesions and muscle damage.

\section{Nucleotide Sequence Analysis}

Virion RNA was prepared for sequence analysis using IsoQuick (ORCA Research, Inc.). Following resuspension of viral RNA in reverse transcription mix, cDNA was generated as described earlier using primer JRpATG [Romero and Rotbart, 1995; 5'-ACTTGAGCTCCCATT, reverse complement of CVB3/20 nucleotides (nt) 742-756, numbering the $5^{\prime}$ terminal nucleotide as 1; [Chapman et al., 1994]. Ten microliters of a reverse transcriptase reaction was used directly in a PCR as described [Romero and Rotbart, 1995] using the primers JRp65 (5'-ACGGTACCTTTGTGCGCCTGTTTT; CVB3/20 nt 63-86) and JRpATG to generate a $694 \mathrm{bp}$ fragment comprising the $5^{\prime}$ NTR from nt63 through 756. Bands of expected size were excised from agarose gels, purified using GeneClean (Bio101, Inc.) and used as template for sequence analysis. Sequencing was accomplished using the Cyclist Exo-Pfu DNA Sequencing Kit (Stratagene). Sequencing gels were dried and exposed to Kodak X-Omat film. Sequences were analyzed using the GCG suite of software (Genetics Computer Group, Inc., Madison, WI). The 5' NTR sequences derived for this study have been posted on and may be downloaded from the worldwide web at http://www.unmc.edu/Pathology/Myocarditis.

\section{RESULTS}

Of thirteen naturally occurring strains of CVB3, two were cardiovirulent (strains AS and DO). These viruses induced large, widespread inflammatory lesions containing necrotic regions and calcification in every mouse heart (Fig. 1a). For the remainder of the virus strains examined, in general no lesions were observed in any of the six sections examined. A few viruses induced a few, small (about five to 20 infiltrating cells) lesions with no necrosis or calcification in a minority of the hearts (Fig. 1b,c).

The 5' NTR sequence from nt 87-741 [relative to CVB3-20; Tracy et al., 1992] from each viral strain was determined. The relationships of these sequences with those of other published CVB3 $5^{\prime}$ NTR sequences were also compared (Fig. 2) using alignments and a dendrogram generated using the PILEUP program (Genetics Computer Group, Inc.) which uses progressive pairwise alignments between sequences to generate a final alignment. Four potential lineages (A, B, C, D) can be distinguished with sequence identities greater than $87 \%$ within the group. The C lineage contains the five primary laboratory strains, in addition to the AS strain. Five of the six strains in this cluster are cardiovirulent and when $\mathrm{nt} 234 \mathrm{C}$ in the only avirulent strain of this group, CVB3/0, reverts to $\mathrm{U}$, this strain is virulent as well [Tu et al., 1995; Tracy et al., 1996]. Selection of cardiovirulent strains in murine models of myocarditis from strains isolated in one period of time may 


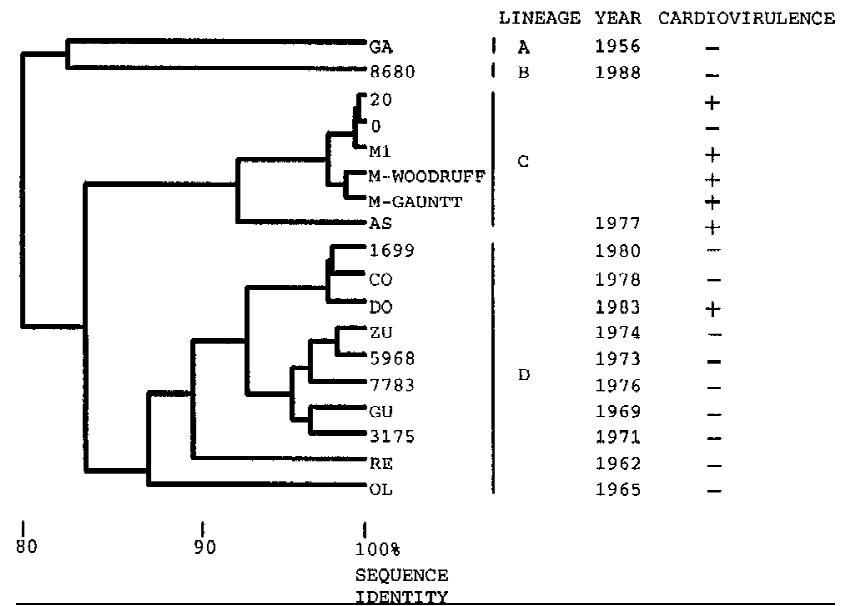

Fig. 2. Dendrogram depicting relationship of the 13 CVB3 strains under study with five previously sequenced CVB3 5' NTR sequences. Dendrogram generated using the PILEUP program (GCG, Madison, WI) on sequences from nt86-742 [relative to CVB3-20, Tracy et al., 1992] and modified to display percentage identity of the sequences. Sequences used for generating the dendrogram were from the strains used in this study and from five laboratory strains whose cardiovirulence and sequences have been determined: CVB3/20 [Tracy et al., 1992], CVB3/0 [Chapman et al., 1994], CVB3/M1 [Klump et al., 1990], CVB3/M-Woodruff [Knowlton et al., 1996], and CVB3/M-Gauntt [Gauntt, unpublished data]. Year is year of isolation of virus strain. + denotes that numerous lesions were seen in heart sections from $\mathrm{C} 3 \mathrm{H} /$ HeJ male mice infected with virus strain at day 10 post-infection [Tracy et al., 1992], - denotes that at best only occasional small lesions were seen and not in all hearts.

have been responsible for this clustering of genetically similar cardiovirulent strains.

Despite the sequence differences in this region of each CVB3 isolate and regardless of the cardiovirulence phenotype, examination of these CVB3 sequences revealed that nt234 was uridine in each sequence. Furthermore, the 5 nucleotide sequence encompassing nt234 described by CVB3 nt232-236 (5'-CGUUA) was invariable not only among CVB3 but all other human enteroviral sequences examined as well (Genbank Release 96.0, 8/96). When this 5mer was located on published global secondary structures of the $5^{\prime}$ NTRs of enteroviruses [Skinner et al., 1989; Le and Zuker, 1990], it was found to be between the primary domains III and IV [Minor, 1992].

\section{DISCUSSION}

Assay of cardiovirulence of the wild-type CVB3 strains in $\mathrm{C} 3 \mathrm{H} / \mathrm{HeJ}$ mice revealed that two of $13 \mathrm{CVB} 3$ strains were significantly cardiovirulent in all mice tested, while the remaining 11 strains were minimally, if at all, cardiovirulent. Two previous studies examined many of these same strains in the CD-1 mouse strain [Tracy and Gauntt, 1987; Gauntt and Pallansch, 1996]. These studies suggest that the great majority of CVB3 strains examined are non-cardiovirulent when tested in mice. The strain CVB3/AS (Fig. 1a) produced myocarditic lesions in both $\mathrm{CD}-1$ and $\mathrm{C} 3 \mathrm{H}$ mice, while the strain CVB3/ZU was scored as virulent in studies in CD-1 mice [Tracy and Gauntt, 1987; Gauntt and Pallansch, 1996] but produced 10-fold fewer lesions than
$\mathrm{AS}$ and was one of the strains in the present study that was avirulent (Fig. 1b,c). Although the mouse strain used can greatly affect the degree of disease induced by cardiovirulent CVB3 [Khatib et al., 1987], C3H/HeJ male mice are highly sensitive to CVB3-induced myocarditis [Kiel et al., 1989; Tracy et al., 1992]. Greater susceptibility to CVB3-induced myocarditis of CD-1 mice may account for the cardiovirulence difference of CVB3/ZU in this study and previous studies.

Sequence analysis of these CVB3 strains demonstrated that nt234 was invariably uridine. Due to this invariance of sequence in CVB3 strains regardless of the established pathogenicity of the virus, nt234U cannot be a determinant of naturally occurring cardiovirulence for CVB3 and must be viewed as a mutation. The 5mer sequence encompassing nt234 (CVB3 context nt232-234, 5'-CGUUA) is completely conserved in all published human enterovirus sequences and in these CVB3 strains. This 5 mer is not located within an established secondary structure domain [Skinner et al., 1989; Le and Zuker, 1990], but is included within the boundaries of the internal ribosome entry site critical for enterovirus translation as defined in studies of polioviruses [Meerovitch et al., 1991; Nicholson et al., 1991; Pestova et al., 1991] and the site of major determinants of poliovirus attenuation [reviewed in Minor, 1992]. Despite this location, analysis of CVB3/0 and CVB3/20 infected murine fetal heart fibroblasts shows no significant differences in viral protein translation [Tu et al., 1995; Tracy and Chapman, unpublished observations]. However, viral transcription in murine and human cardiac cell cultures is significantly disturbed when nt234 is present as C [Tu et al., 1995] or G [S. Tracy, N. Chapman, J. Romero, unpublished data]. This site, and perhaps other sites within the 5 mer, may represent a useful site(s) for targeting mutations to artificially attenuate CVB3 and possibly other enteroviruses. That natural CVB3 isolates vary in cardiovirulence and yet are completely conserved in sequence in this region indicates sites elsewhere in the genome are important for determination of cardiovirulence in CVB3 strains circulating in the human population.

\section{ACKNOWLEDGMENTS}

We thank J. Smith Leser and Melanie Fron for expert technical assistance. This work was supported by grants from the Public Health Service (N.M.C., J.R.R., S.T.), the American Heart Association (N.M.C., S.T.), the Edna Ittner Foundation (J.R.R.).

\section{REFERENCES}

Chapman NM, Tu Z, Tracy S, Gauntt CJ (1994): An infectious cDNA copy of the genome of a non-cardiovirulent coxsackievirus B3 strain: Its complete sequence analysis and comparison to the genomes of cardiovirulent coxsackieviruses. Archives of Virology 135:115-130.

Gauntt CJ, Pallansch MA (1996): Coxsackievirus B3 clinical isolates and murine myocarditis. Virus Research 41:89-99.

Gauntt CJ, Trousdale MD, LaBadie DR, Paque RE, Nealon T (1979): Properties of coxsackievirus B3 variants which are amyocarditic or myocarditic for mice. Journal of Medical Virology 3:207-220. 
Khatib R, Probert A, Reyes MP, Khatib G, Chason JL (1987): Mouse strain-related variation as a factor in the pathogenesis of coxsackievirus B3 murine myocarditis. Journal of General Virology 68: 2981-2988.

Kiel RJ, Smith FE, Chason J, Khatib R, Reyes MP (1989): Coxsackievirus B3 myocarditis in C3H/HeJ mice: Description of an inbred model and the effect of exercise on virulence. European Journal of Epidemiology 5:348-350.

Klump WM, Bergmann I, Muller BC, Ameis D, Kandolf R (1990): Complete nucleotide sequence of infectious coxsackievirus B3 cDNA: Two initial 5' uridine residues are regained during plusstrand RNA synthesis. Journal of Virology 64:1573-1583.

Knowlton KU, Jeon E-S, Berkley N, Wessely R, Huber S (1996): A mutation in the puff region of VP2 attenuates the myocarditic phenotype of an infectious cDNA of the Woodruff variant of coxsackievirus B3. Journal of Virology 70:7811-7818.

Le SY, Zuker M (1990): Common structures of the 5' non-coding RNA in enteroviruses and rhinoviruses. Thermodynamical stability and statistical significance. Journal of Molecular Biology 216:729-741.

Martino TA, Liu P, Petric M, Sole MJ (1995): Enteroviral myocarditis and dilated cardiomyopathy: A review of clinical and experimental studies. In Rotbart HA (ed): "Human Enterovirus Infections." Washington, DC: ASM Press, pp 291-351.

Meerovitch K, Nicholson R, Sonenberg N (1991): In vitro mutational analysis of cis-acting RNA translational elements within the poliovirus type $25^{\prime}$ untranslated region. Journal of Virology 65: 5895-5901.

Minor PD (1992): The molecular biology of poliovaccines. Journal of General Virology 73:3065-3077.

Nicholson R, Pelletier J, Le SY, Sonenberg N (1991): Structural and functional analysis of the ribosome landing pad of poliovirus type 2: In vivo translation studies. Journal of Virology 65:5886-5894.

Pestova T, Hellen C, Wimmer E (1991): Translation of poliovirus RNA: Role of an essential cis-acting oligopyrimidine element within the $5^{\prime}$ nontranslated region and involvement of a cellular 57-kilodalton protein. Journal of Virology 65:6194-6204

Romero JR, Rotbart HA (1995): Sequence analysis of the downstream 5 ' nontranslated region of seven echoviruses with different neurovirulence phenotypes. Journal of Virology 69:1370-1375.

Skinner MA, Racaniello VR, Dunn G, Cooper J, Minor PD, Almond JW (1989): New model for the secondary structure of the $5^{\prime}$ noncoding RNA of poliovirus is supported by biochemical and genetic data that also show that RNA secondary structure is important in neurovirulence. Journal of Molecular Biology 207:379-392.

Tracy S, Chapman NM, Tu Z (1992): Coxsackievirus B3 from an infectious cDNA copy of the genome is cardiovirulent in mice. Archives of Virology 122:399-409.

Tracy S, Chapman NM, Romero J, Ramsingh AI (1996): Genetics of coxsackievirus B cardiovirulence and inflammatory heart muscle disease. Trends in Microbiology 4:175-179.

Tracy S, Gauntt C (1987): Phenotypic and genotypic differences among naturally occurring coxsackie virus B3 variants. European Heart Journal 8(Suppl.):445-448.

Tu Z, Chapman NM, Hufnagel G, Tracy S, Romero JR, Barry WH, Zhao L, Currey K, Shapiro B (1995): The cardiovirulent phenotype of coxsackievirus B3 is determined at a single site in the genomic $5^{\prime}$ nontranslated region. Journal of Virology 69:4607-4618.

Woodruff JF (1980): Viral myocarditis. A review. American Journal of Pathology 101:425-484. 